\title{
Plasma Treatment of Crosslinked Polyethylene Tubes for Improved Adhesion of Water- based Paints
}

\author{
Gabriel Ferreira Fernandes ${ }^{a}$, Milena Kowalczuk Manosso Amorim ${ }^{a}$,
}

Rafael Gustavo Turri ${ }^{a}$, Paulo Silas Oliveira ${ }^{a, c}$, Ismael Leandro Graff ${ }^{b}$, Elidiane Cipriano Rangel ${ }^{a}{ }^{\mathbb{D}}$, Steven Frederick Durrant ${ }^{a}$ (D)

${ }^{a}$ Laboratório de Plasmas Tecnológicos, Instituto de Ciência e Tecnologia de Sorocaba, Universidade Estadual Paulista - UNESP, Avenida Três de Marco, 511, Alto da Boa Vista, 18087-180, Sorocaba, SP, Brasil

${ }^{b}$ Departamento de Física, Universidade Federal de Paraná, Curitiba, PR, Brasil

'Instituto Federal de Educação, Ciência e Tecnologia de São Paulo, Campus Registro, SP, Brasil

Received: November 28, 2017; Revised: August 21, 2018; Accepted: October 25, 2018

Cold plasmas fed trichloromethane-argon mixtures were used to treat cross-linked polyethylene (PE) to improve the adhesion of water-based paint. The effects of the plasma treatment undertaken at different percentages of $\mathrm{CHCl}_{3}$ in the plasma feed, $\mathrm{C}_{\mathrm{Cl}}$, were investigated using Infrared Spectroscopy in Diffuse Reflection (DR) mode, Scanning Electron Microscopy (SEM), Energy Dispersive X-ray Spectroscopy (EDS), X-ray Photoelectron Spectroscopy (XPS), goniometry for surface contact angle measurements, profilometry for roughness measurements, and paint adhesion tests. All the treatments modify the surfaces by introducing chlorine. Oxygen is present in the bulk and on the surfaces of the treated and untreated material. The treatments do not alter the bulk, but tend to increase the surface roughness and contact angle. When $\mathrm{CHCl}_{3}$ is present in the plasma subsequent paint adhesion is improved from a very poor classification of 4 to an excellent classification of 0 (assessed according to the appropriate Brazilian standards (BS EN ISO 2409:2007 and BS 3900-E6:2007A)). Surface roughness is not increased at low $\mathrm{C}_{\mathrm{Cl}}$ but improved paint adhesion occurs for all $\mathrm{C}_{\mathrm{Cl}}>0$. Although the causes of the improved paint adhesion with the plasma treatment are unclear, they may be related to the plasma activation of unsaturated carbon and oxygen functionalities.

Keywords: paint, roughness, cold plasma, trichloromethane, adhesion.

\section{Introduction}

Plasma treatment is well established for the surface modification of diverse materials ${ }^{1}$. For example, air cold plasmas have been used to improve the adhesion of acrylic paint to 2024 aluminum alloy ${ }^{2}$, which is used in aircraft manufacture and therefore has to resist harsh conditions, such as the presence of moisture, organic materials, and wide temperature fluctuations. Such treatments allow the elimination of an otherwise essential surface-cleaning step and a reduction in the amount of primer needed, potentially reducing the overall painting time and the paint weight, the latter being an important consideration for aircraft. Plasma-deposited films have also been used as promoters for the adhesion of alkyd paint to titanium alloy (Ti-6Al-4V) substrates ${ }^{3}$. Several silanes were used as monomers, improving the adhesion of the paint under monomer-deficient conditions. Improved adhesion in the cases mentioned here are attributable to increases in surface roughness and decreases in surface contact angle induced by the treatments, which lead to increased covalent, van der Waal's or hydrogen bonding ${ }^{4}$.

*e-mail: steven.durrant@unesp.br
Wolkenhauer et $\mathrm{al}^{5}$ examined the adhesion of paints (and adhesives) on wood-plastic composites following atmospheric dielectric barrier discharge plasma treatment in air. Contact angle measurements, atomic force microscopy and tensile bond strength testing were applied. These revealed that the polar component of the surface energy and the roughness increased under treatment. The treatments also improved adhesion of water-borne, solvent-borne and oil-based paints.

The efficacy of improving urethane paint adhesion to a polypropylene car bumper using oxygen, water, and acetylene plasmas instead of a primer has been reported ${ }^{6}$. Each treatment increased the adhesion strengths, as assessed by lap-shear tensile strength values, in dry conditions but the treatment in acetylene was more robust when subsequently exposed to wet conditions. The improved adhesion in the presence of acetylene is attributed to the existence of reactive unsaturated hydrocarbons and oxidized hydrocarbons in the deposited film.

Irradiation of poly(ethylene glycol-co-1,3/1,4 cyclohexanedimethanol terephthalate (PETG) using $\mathrm{H}_{2}$ and $\mathrm{CF}_{4}$ plasmas typically increased surface roughness and decreased surface contact angles as measured by profilometry and goniometry, respectively ${ }^{4}$. Paint adhesion was strongest 
when wettability and work of adhesion were increased. (Work of adhesion is defined as the reversible thermodynamic work that is needed to separate the interface from the equilibrium state of two phases to a separation distance of infinity).

As summarized elsewhere ${ }^{7}$, chlorine-containing plasmas have been employed to modify the surfaces of polymers. For example, when polypropylene is treated in $\mathrm{CCl}_{4}$ plasmas or $\mathrm{CHCl}_{3}$ plasmas, chlorine and often also oxygen is introduced into the treated surface, changing the surface roughness and surface contact angle. Such treatments are simple, one-step, rapid, dry, almost pollution free, and may readily be automated and scaled-up as required.

In the present study, the use of cold $\mathrm{CHCl}_{3}$ - Ar plasmas to improve the adhesion of water-based paint to crosslinked polyethylene material used in fuel gas installations is investigated. The motivation for this is to be able to use these tubes for external use. Obtaining good paint adhesion is difficult but necessary for such outside use, which is a common requirement in Brazil. Infrared Spectroscopy in Diffuse Reflectance (DR) mode, Energy Dispersive X-ray Spectroscopy (EDS) and X-ray Photoelectron Spectroscopy (XPS), were used to investigate the chemical structure and composition of the treated polymer. Scanning Electron Microscopy (SEM) was used to confirm surface morphologies. Goniometry, profilometry, and a Brazilian standard paintadhesion test were employed to reveal surface contact angles, surface roughness, and quality of adhesion, respectively.

\section{Experimental}

\subsection{Plasma treatment}

Plates of rough dimensions $12 \mathrm{~mm}$ x $7 \mathrm{~mm}$ x 1mm were produced by cutting, opening out, and flattening pieces of high density cross-linked polyethylene tube, PE-Xc (HENCO, Doorn, Netherlands).

The substrates were cleaned by immersion in an ultrasonic bath containing 50\% water and 50\% detergent (DET LIMP $\mathrm{S} 32$ ) for 8 minutes, then rinsed in running water, immersed in an ultrasonic bath of distilled deionized water for $8 \mathrm{~min}$., rinsed again in running water, and finally treated in an ultrasonic bath of isopropyl alcohol for $8 \mathrm{~min}$. and dried in a hot air current.

Treatments were undertaken in a Radiofrequency PECVD system consisting of a cylindrical stainless-steel chamber equipped with internal circular, horizontal electrodes. Power $(60 \mathrm{~W})$ was fed to the lower electrode from a $13.56 \mathrm{MHz}$ power supply (TOKYO HY-POWER, MB-300) via a capacitance matching box; the upper electrode was earthed. Cleaned plates were placed on the powered electrode for treatment. Initially the chamber was evacuated to a pressure of $\sim 10$ mTorr. Mixtures of argon and tricloromethane were used for the treatments. Trichloromethane vapor was introduced to the chamber from glass vials containing liquid trichloromethane via needle valves (EDWARDS, LV10-K). Argon (99.99\% pure, WHITE MARTINS, Brazil) was supplied from a cylinder via an electronic flowmeter (DATAMETRICS, USA). During treatments the chamber was evacuated continuously using a rotary vane pump (EDWARDS E2M18). Mixtures of argon and trichloromethane were used at a total pressure of 100 mTorr. The partial pressure of chloroform expressed as a percentage of the total pressure, $\mathrm{C}_{\mathrm{Cl}}$, was varied from 0 to $100 \%$. The $\mathrm{C}_{\mathrm{Cl}}$ value of $0 \%$ represents the untreated sample. Pressures were monitored using a Pirani gauge (AGILENT TECNOLOGIES LTDA). A treatment time of $15 \mathrm{~min}$. was used throughout. Figure 1 shows the treatment system.

\subsection{Characterizations}

A JASCO FTIR-410 spectrophotometer was used for the diffuse reflectance (DR) infrared spectroscopic analyses for wavenumbers in the 4000 to $400 \mathrm{~cm}^{-1}$ range. Each spectrum comprised 128 scans; a resolution of $4 \mathrm{~cm}^{-1}$ was achieved.

Surface morphology of the treated surfaces was studied using a JEOL JSM-6010 scanning electron microscope equipped with a secondary electron detector. Micrographs were obtained using the secondary electron signal at an accelerating voltage of $3 \mathrm{kV}$. Chemical composition of the material was studied using Energy Dispersive X-ray Spectrometry (EDS).

X-ray Photoelectron Spectroscopic (XPS) analyses obtained using a VG Microtech-ESCA 3000, which employs a beam of $\mathrm{MgK}_{\alpha}$ radiation of $1253,6 \mathrm{eV}$ at an incidence angle of $45^{\circ}$, provided additional compositional information. A resolution of $\sim 0.8 \mathrm{eV}$ was achieved. Shirley background correction was employed.

Surface wettability was determined from contact angle $(\theta)$ data taken using a RAMÉ-HART 100-00 goniometer. To obtain a mean value and its uncertainty, a total of 30 measurements were made on three drops of deionized water $(0.2 \mu \mathrm{L})$ placed at different regions of the sample surface.

Surface roughness, $\mathrm{R}_{\mathrm{a}}$, i.e. the arithmetic average of the absolute values of the profile height deviations from the mean line, was calculated using ten points from each of three $250 \mathrm{~mm}$-long linear scans obtained using a profilometer (VEECO, Dektak ${ }^{3} \mathrm{ST}$ ).

Paint adhesion tests were carried out on the untreated and treated substrates using the procedures given in the internationally accepted Brazilian standards BS EN ISO 2409:2007 and BS 3900-E6:2007A. White premium acrylic paint (FORTY DUBAI IND E COM DE TINTAS E VERNIZES LTDA, Brazil) for interior and exterior use was applied to the substrates.

The paint was homogenized with $20 \%$ water (by mass in relation to the original paint mass). An initial coat of paint was applied using a polyethylene roller. The painting was repeated after 4 and after 8 hours. On the following day the adhesion tests were undertaken. 


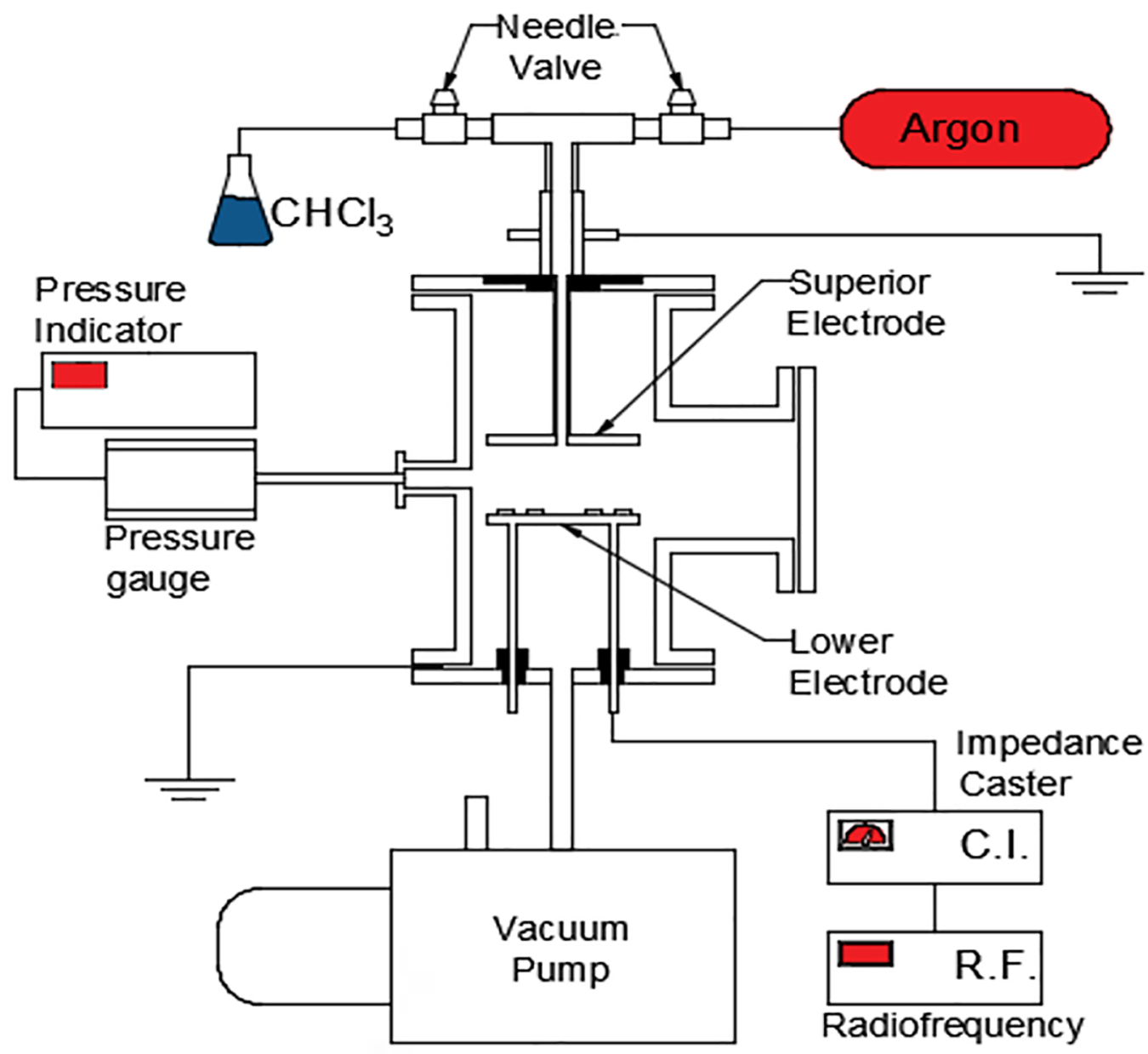

Figure 1. The plasma treatment system.

Cuts along square grid lines were made using a sharp knife. Any excess paint was then lightly brushed off. A standard tape was pressed to the painted surface uniformly using a rubber eraser. The tape was then removed at an angle of $60^{\circ}$ between it and the surface of the sample at a constant rate. This procedure was triplicated for each sample.

\section{Results and Discussion}

Figure 2 shows the diffuse reflectance (DR) infrared spectra of the untreated and treated PE. As DR is not a strictly surface technique, surface changes produced by the plasma treatments are not evident in the sequence of spectra. Absorptions owing to the presence of $\mathrm{CH}$ symmetrical and asymmetrical stretching modes in $\mathrm{CH}_{2}$ and $\mathrm{CH}_{3}$ groups at around $2923 \mathrm{~cm}^{-1}$ and $2852 \mathrm{~cm}^{-1}$ are seen. The band at around $3600 \mathrm{~cm}^{-1}$ is attributed to stretching vibrations in hydroxyl groups. Two absorptions at about 2020, $1896 \mathrm{~cm}^{-1}$ may be due to vibrations in carbonyl groups or $\mathrm{C}=\mathrm{C}=\mathrm{C}$ structures. The absorption at about $1700 \mathrm{~cm}^{-1}$ is attributed to stretching in carbonyl groups. There are similar attributions to peaks

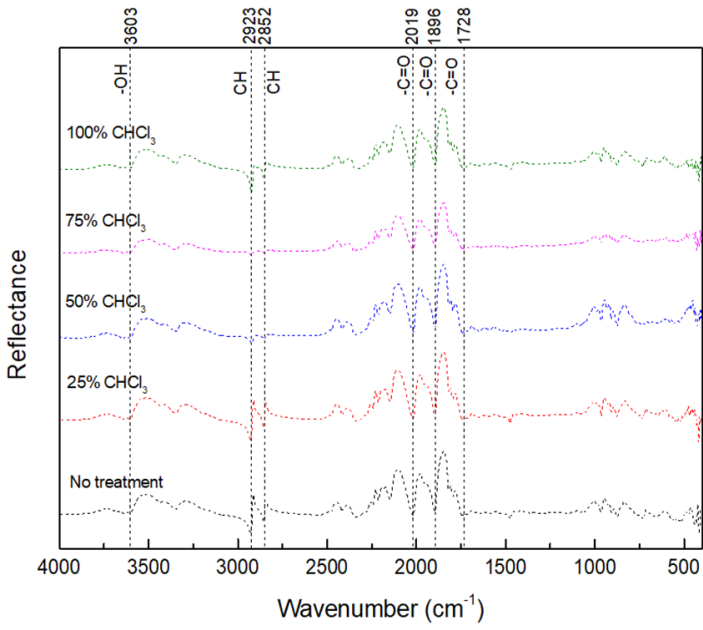

Figure 2. DR spectra in the 400 to $4000 \mathrm{~cm}^{-1}$ range of the $\mathrm{PE}$ treated at different $\mathrm{C}_{\mathrm{Cl}}$.

in infrared spectra of, for example, untreated low density $\mathrm{PE}$ in the literature ${ }^{8}$. No absorptions due to $\mathrm{C}_{-} \mathrm{Cl}_{\mathrm{x}}$ groups 
are detected in the spectra of the treated material. This is accounted for by the relatively great sampling depth and the expected low sensitivity of $\mathrm{C}-\mathrm{Cl}_{\mathrm{x}}$ absorptions.

Figure 3 shows scanning electron micrographs of the treated and untreated PE. There is an apparent tendency to rougher surfaces at high values of $\mathrm{C}_{\mathrm{Cl}}$, especially at $\mathrm{C}_{\mathrm{Cl}}$ $\geq 75 \%$. Some free chlorine is expected to be produced in plasmas containing $\mathrm{CHCl}_{3}$, thus surface etching by chlorine may account for the increased roughness.

As shown in Figure 4, the elemental composition (C, $\mathrm{Cl}, \mathrm{O}$ ), estimated using EDS, varies with $\mathrm{C}_{\mathrm{Cl}}$. The relative carbon content decreases while that of chlorine increases. In thin films produced by PECVD with a source of chlorine in the plasma feed the chlorine film concentration typically increases with increasing $\mathrm{C}_{\mathrm{Cl}}{ }^{7,9}$. Similarly, for treatment in $\mathrm{CHCl}_{3}$ plasmas, holding other system parameters constant (e.g. applied power and treatment time) it is anticipated that the chlorine content of the surface increases with increasing $\mathrm{C}_{\mathrm{Cl}}$, unless saturation occurs. Polypropylene, for example, has been chlorinated in $\mathrm{CHCl}_{3}$ plasmas ${ }^{10}$.

As indicated by the infrared analyses (Fig. 2), the untreated $\mathrm{PE}$ contains some oxygen. Figure 4 shows that [O] varies roughly over the range 3 to 6 at.\%. Some post-deposition incorporation of oxygen as a result of reactions between radicals in the film and ambient oxygen or water or both is

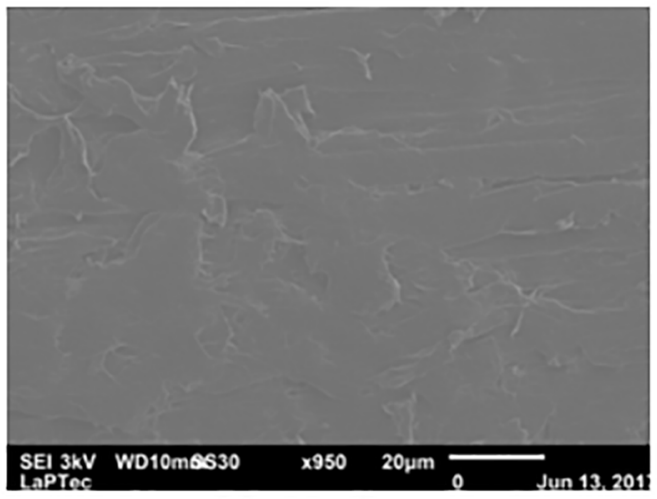

(a) No Treatment

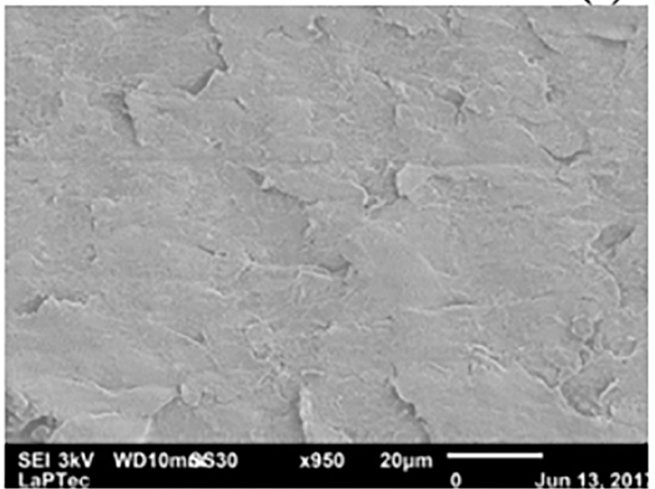

(b) $25 \%$ of $\mathrm{CHCl}_{3}$

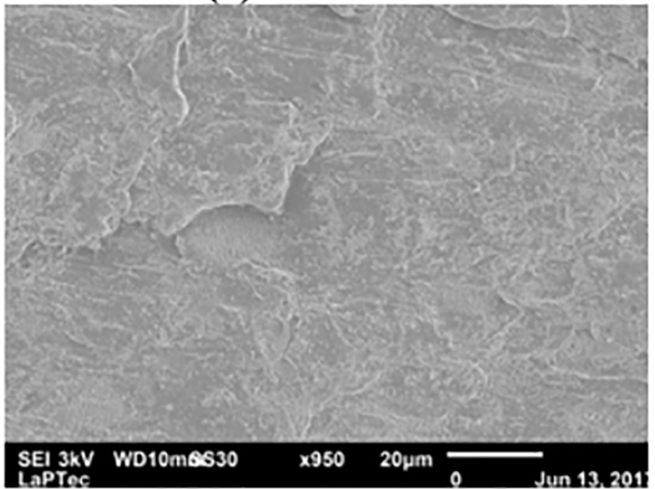

(d) $75 \%$ of $\mathrm{CHCl}_{3}$

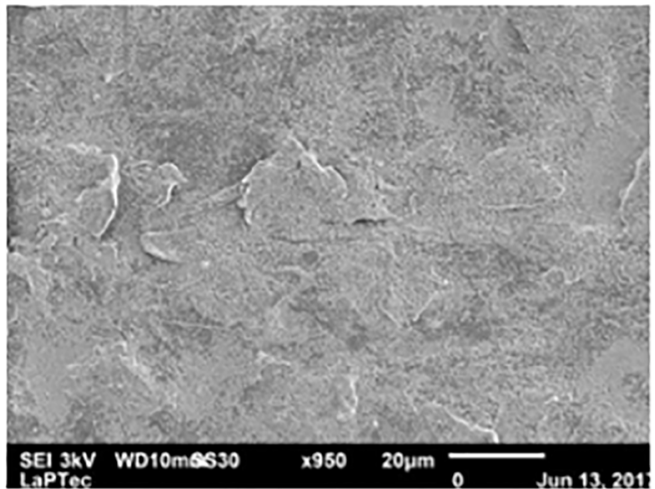

(c) $50 \%$ of $\mathrm{CHCl}_{3}$

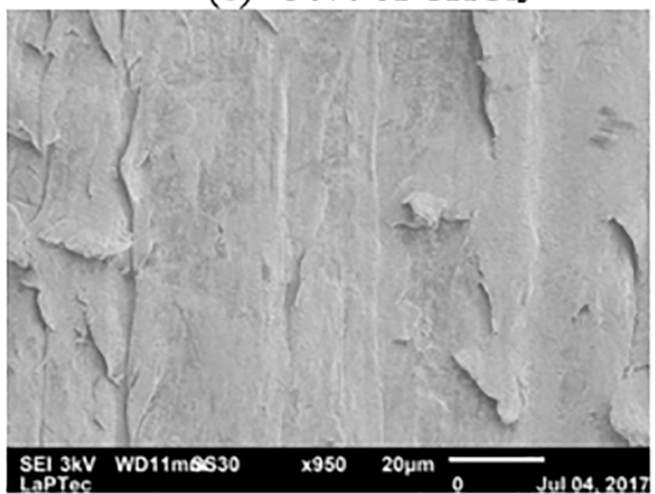

(e) $100 \%$ of $\mathrm{CHCl}_{3}$

Figure 3. Scanning electron micrographs of $\mathrm{PE}$ treated at $\mathrm{C}_{\mathrm{Cl}}=0 \%$; (b) $\mathrm{C}_{\mathrm{Cl}}=25 \%$; (c) $\mathrm{C}_{\mathrm{Cl}}=50 \%$; (d) $\mathrm{C}_{\mathrm{Cl}}=75 \%$; (e) $\mathrm{C}_{\mathrm{Cl}}=100 \%$. 


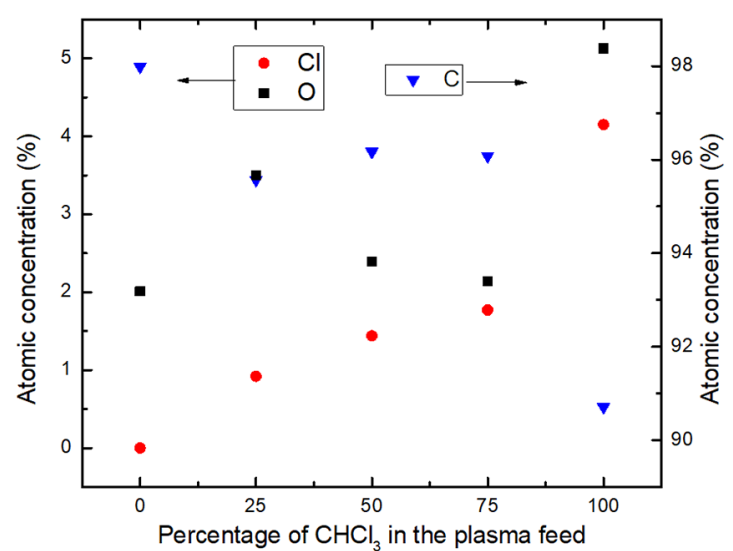

Figure 4. Elemental composition determined using EDS as a function of $\mathrm{C}_{\mathrm{Cl}}$.

well-known for plasma polymers ${ }^{11}$; similar interactions may explain the slight increase in $[\mathrm{O}]$ observed with increasing $\mathrm{C}_{\mathrm{C}}$.

The untreated and treated samples were also analyzed using XPS but quantification of the elements present was limited by the following factors: (i) insufficient resolution did not allow quantification based on the $2 \mathrm{p} 3 / 2$ and $2 \mathrm{p} 1 / 2$ peaks; (ii) the presence of a few extraneous elements such as $\mathrm{Si}$ and $\mathrm{Na}$ made the deconvolution of the $\mathrm{C} 1 \mathrm{~s}$ peaks unreliable; (iii) chlorine could not be quantified without the $\mathrm{Cl} 2$ s peak, which was only detectable when chlorine was present above a minimum concentration. This occurred for the surfaces for which $\mathrm{C}_{\mathrm{Cl}}$ was $50 \%$ or greater; the results were as follows. For $\mathrm{C}_{\mathrm{Cl}}$ of $50 \%, 75 \%$ and $100 \%$, respectively, $\mathrm{Cl}$ passed from 38.7 to 49 to 46.8 at. $\%$; C passed from 40.4 to 36.9 to 46.9 at. $\%$; O passed from 20.8 to 14.1 to 6.3 at. $\%$.

Figure 5 shows XPS survey spectra of the untreated and treated polyethylene. The tendencies in the peak heights show higher values of $\mathrm{Cl}$ and lower values for $\mathrm{O}$ as $\mathrm{C}_{\mathrm{Cl}}$ is increased.

EDS measurements generally reflect the elemental concentrations in the bulk but can detect, for example, surface $\mathrm{Cl}$ when it is present at a sufficiently high concentration. The bulk PE contains oxygen. Therefore the $[\mathrm{O}]$ measured by EDS may indicate small variations in the concentration of this element in the bulk, while the XPS values (where available) indicate surface concentrations. Thus oxygen is present in both the bulk and the surface of all the films. The role of oxygen is important and merits future study. For example, atmospheric moist air plasma treatment of steel can reduce contact angles by about $20^{\circ}$ and potentially improve paint adhesion ${ }^{12}$. Oxygen surface cleaning and oxidation also play key roles in the increased hydrophilicity of the treated surfaces. Similarly, surface cleaning and activation are responsible for reducing surface contact angles on aluminum exposed to an atmospheric plasma from $87^{\circ}$ to $8^{\circ}{ }^{13}$.

The trends in $[\mathrm{Cl}]$ as a function of $\mathrm{C}_{\mathrm{Cl}}$ observed by EDS and XPS are compatible on the assumption that on the surface $\mathrm{Cl}$ tends to displace $\mathrm{O}$. Thus at high $\mathrm{C}_{\mathrm{Cl}}$ the surface is chlorinated at the expense of oxygen, while the bulk contains oxygen but no chlorine.

Figure 6 shows the water surface contact angle, $\theta$, as a function of $\mathrm{C}_{\mathrm{Cl}}$. $\mathrm{As}_{\mathrm{Cl}}$ increases, $\theta$ increases by only about 20 degrees over the whole range of $\mathrm{C}_{\mathrm{Cl}}$. Figure 7 shows the surface roughness as a function of $\mathrm{C}_{\mathrm{Cl}}$. Roughness tends to increase as a function of $\mathrm{C}_{\mathrm{Cl}}$. This increase is compatible with the surface morphologies shown previously (Fig. 3). Roughness,

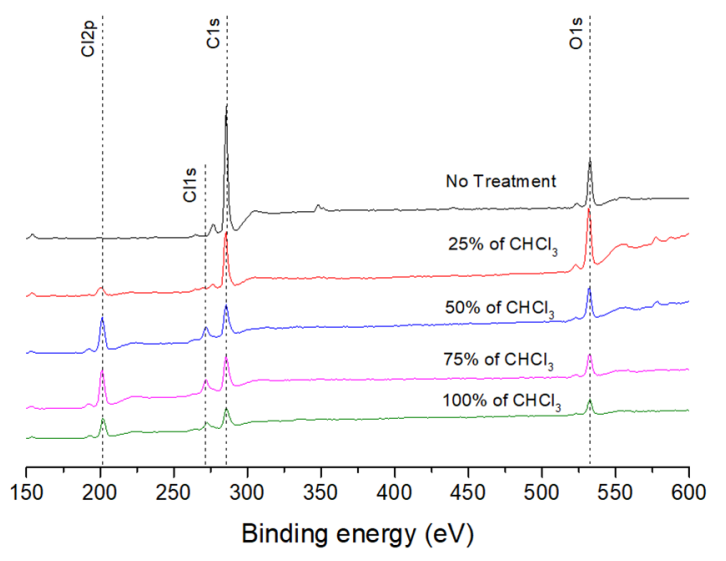

Figure 5. XPS survey spectra of the untreated and treated polyethylene.

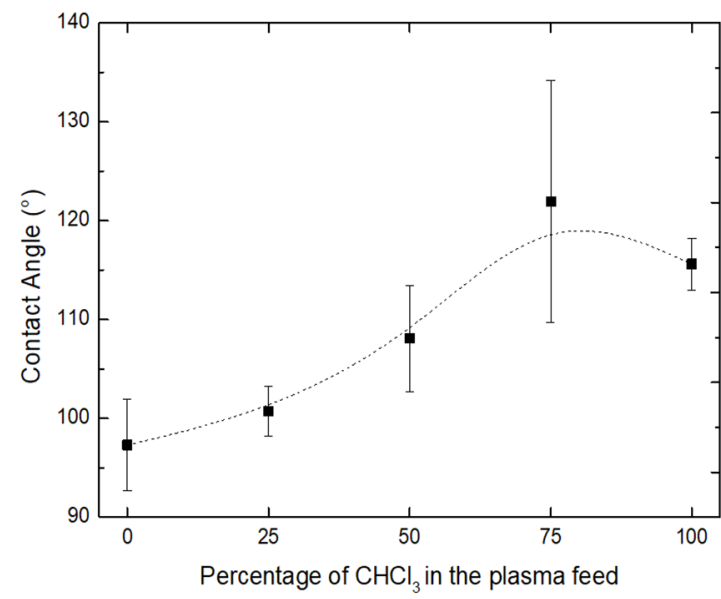

Figure 6. Surface contact angle as a function of $\mathrm{C}_{\mathrm{Cl}}$.

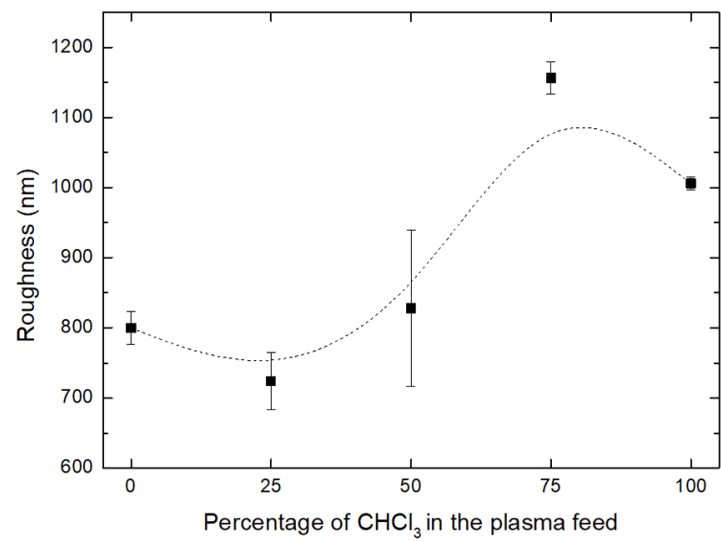

Figure 7. Surface roughness as a function of $\mathrm{C}_{\mathrm{Cl}}$. 
chemical composition, and structure influence $\theta$. Increased roughness correlates roughly with increased $\theta$.

While greater values of $\theta$ may tend to impede paint adhesion, greater roughness may improve it. Figure 8 (a,b,c,d,e) shows the results of the paint adhesion tests for the untreated and treated PE. All of the treatments are highly effective independently of $\mathrm{C}_{\mathrm{Cl}}\left(\mathrm{C}_{\mathrm{Cl}}>0\right)$. For $\mathrm{C}_{\mathrm{Cl}}=25 \%, \theta$ increases and roughness decreases with respect to the untreated

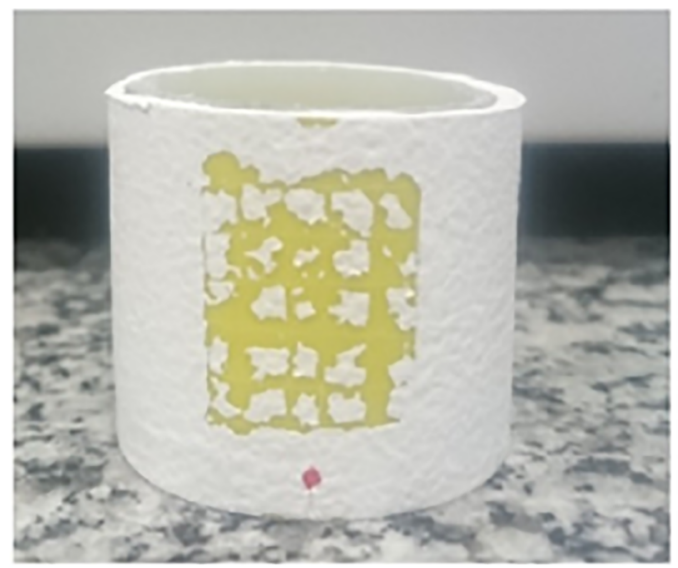

(a) No Treatment

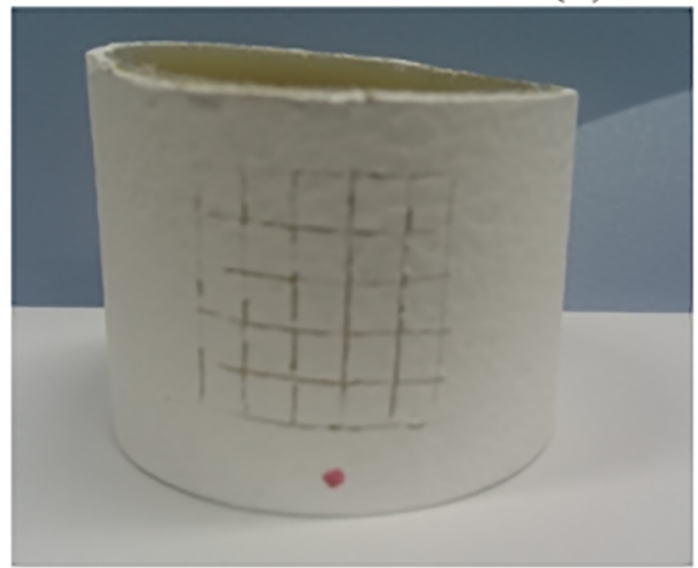

(b) $25 \%$ of $\mathrm{CHCl}_{3}$

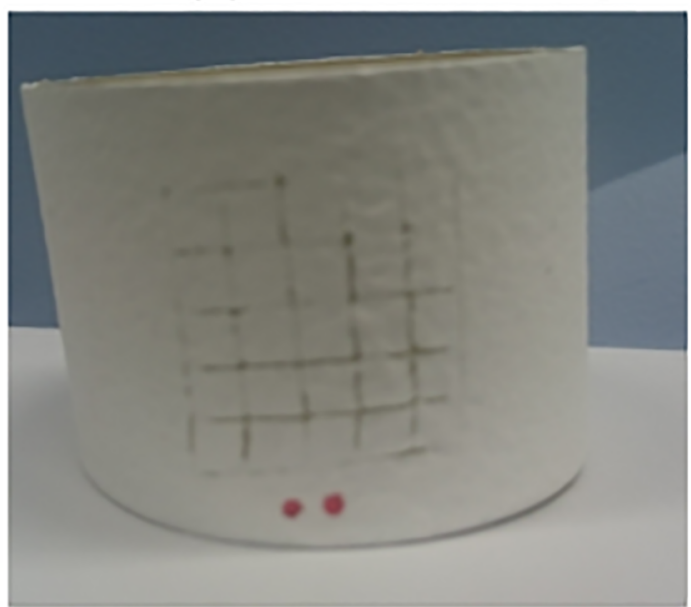

(d) $75 \%$ of $\mathrm{CHCl}_{3}$

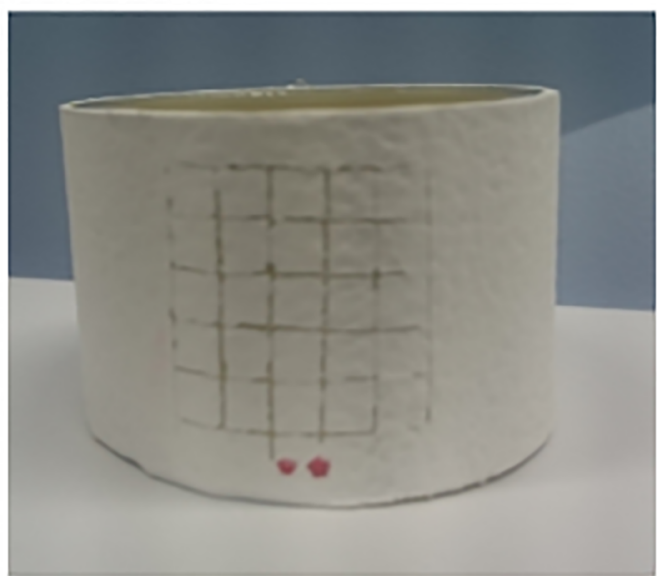

(c) $50 \%$ of $\mathrm{CHCl}_{3}$

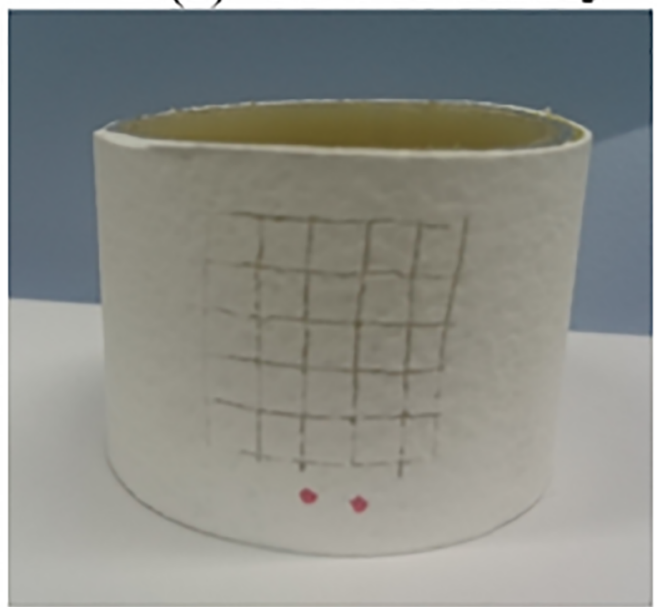

(e) $100 \%$ of $\mathrm{CHCl}_{3}$

Figure 8. Photographs of the paint adhesion tests on PE treated at $\mathrm{C}_{\mathrm{Cl}}=0 \%$ (untreated); (b) $\mathrm{C}_{\mathrm{Cl}}=25 \%$; (c) $\mathrm{C}_{\mathrm{Cl}}=50 \%$; (d) $\mathrm{C}_{\mathrm{Cl}}=75 \%$; (e) $\mathrm{C}_{\mathrm{Cl}}=100 \%$. 
materials. Both effects are expected to reduce paint adhesion but this is not observed. Therefore, for this case the cause of the improved adhesion must lie elsewhere; for example, in the presence of $\mathrm{Cl}$ or the combination of chemical structures present on the treated surface. Regarding the latter, the untreated material contains unsaturated carbon bonds and oxygenated functionalities, which may be activated and altered by the treatment, producing free radicals and dangling bonds as well as new oxygen-containing species. These then possibly react with the acryloyl, $\mathrm{H}_{2} \mathrm{C}=\mathrm{CH}-\mathrm{C}(=\mathrm{O})$-, components of the paint.

Table 1 shows the classification of the adhesion test results according to the Brazilian standards (BS EN ISO 2409:2007 and BS 3900-E6:2007A). The results obtained by painting the untreated PE clearly correspond to classification 4, which represents an extremely poor performance. In contrast, for all of the plasma-treated PE samples paint adhesion at level 0 is obtained.

\section{Conclusions}

Trichloromethane-argon plasma treatment of high density crosslinked PE over a wide range of partial pressures greatly improves water-based paint adhesion. The treatment modifies the surface oxygen content and produces surface chlorination, which is greater at greater $\mathrm{C}_{\mathrm{Cl}}$. The improvement in adhesion is not readily explained by the changes in surface contact angle or roughness induced by the treatment, but

Table 1. Classification of test results

\begin{tabular}{|c|c|c|}
\hline Classification & Description & $\begin{array}{l}\text { Appearance of surfasse of cross-cut from which flaking has } \\
\text { occurred(Example for six parallel cuts) }\end{array}$ \\
\hline
\end{tabular}

0

The edges of the cuts are completely smooth; none of the squares of the lattice is detached.

Detachment of small flakes of the coating at the intersections of the cuts. A cross-cut area not greater than $5 \%$ is affected.

The coating has flaked along the edges and/or at the intersections of the cuts. A cross-cut area greater than $5 \%$, but not greater than $15 \%$, is affected.

The coating has flaked along the edges of the cuts partly or wholly in large ribbons, and/or it has flaked partly or wholly on different parts of the squares. A cross-cut area greater than $15 \%$, but not greater than $35 \%$,is affected.

The coating has flaked along the edges of the cuts in large ribbons and/or some squares have detached partly or wholly. A cross-cut area greater than $35 \%$, but not greater than $65 \%$, is affected.
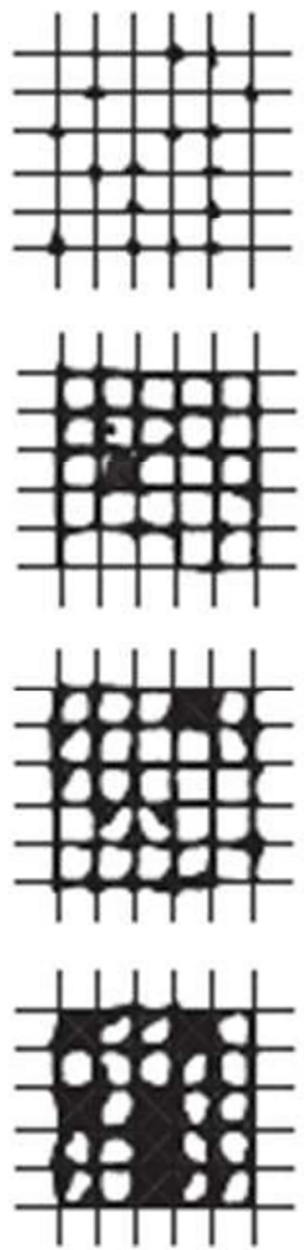
incorporation of chorine and activation of unsaturated carbon groups and oxygen-containing functionalities may play a role. However, the improved adhesion results are robust and have obvious application.

\section{Acknowledgements}

The authors thank FAPESP (2014/21594-9) and CNPq for financial support. Two of us, GFF and MKMA, gratefully acknowledge support from UNESP (Bolsa Reitoria) and CAPES, respectively. This study was financed in part by the Coordenação de Aperfeiçoamento de Pessoal de Nível Superior - Brasil (CAPES) - Finance code 001.

\section{References}

1. D'Agostino R, ed. Plasma Deposition, Treatment and Etching of Polymers. 1st ed. San Diego: Academic Press; 1990.

2. Polini W, Sorrentino L. Analysis of adhesion in an aggressive environment of a protective paint coating on an aluminium alloy surface treated by air cold plasma. Journal of Adhesion Science and Technology. 2004;18(14):1643-1661.

3. Matsuda Y, Yasuda H. Evaluation of plasma polymers of silanes as adhesion promoters for organic paint. Thin Solid Films. 1984;118(2):211-224.

4. Salapre HS III, Cosiñero HSO, Suarez BAT, Bacaoco MY, Nuñez JAP, Guittard F, et al. Gas discharge plasma treatment of poly(ethylene glycol-co-1,3/1,4 cyclohexanedimethanol terephthalate) for enhanced paint adhesion. Journal of Vacuum Science \& Technology A. 2016;34(4):041303.
5. Wolkenhauer A, Avramidis G, Huaswald E, Militz H, Viöl W. Plasma Treatment of Wood-Plastic Composites to Enhance their Adhesion Properties. Journal of Adhesion Science and Technology. 2008;22(16):2025-2037.

6. Cho DL, Shin KH, Lee WJ, Kim DH. Improvement of paint adhesion to a polypropylene bumper by plasma treatment. Journal of Adhesion Science and Technology. 2001;15(6):653-664.

7. Turri R, Davanzo CU, Schreiner W, Dias da Silva JH, Appolinario MB, Durrant SF. Structural and optical properties of chlorinated plasma polymers. Thin Solid Films. 2011;520(5):1442-1445.

8. Blythe AR, Briggs D, Kendall CR, Rance DG, Zichy VJI. Surface modification of polyethylene by electrical discharge treatment and the mechanism of autoadhesion. Polymer. 1978;19(11):1273-1278.

9. Rossi D, Landers R, Bortoleto JRR, Durrant SF. Characterization of PECVD a-C:H:Si:O:Cl films. Journal of Vacuum Science \& Technology A. 2017;35(4):04D103.

10. Inagaki N, Tasaka S, Suzuki Y. Surface chlorination of polypropylene film by $\mathrm{CHCl} 3$ plasma. Journal of Applied Polymer Science. 1994;51(13):2131-2137.

11. Yasuda H, Bumgarner MO, Marsh HC, Morosoff N. Plasma polymerization of some organic compounds and properties of polymers. Journal of Polymer Science, Polymer Chemistry, Part A. 1976;14(1):195-224.

12. Bárdos L, Baránková H. Cold Atmospheric Plasma Treatment of Steel Buoys for Wave Energy Converters. Plasma Processes and Polymers. 2011;8(7):658-663.

13. Mui T, Silva LLG, Prysiazhnyi V, Kostov KG. Polyurethane paint adhesion improvement on aluminium alloy treated by plasma jet and dielectric barrier discharge. Journal of Adhesion Science and Technology. 2016;30(2):218-229. 